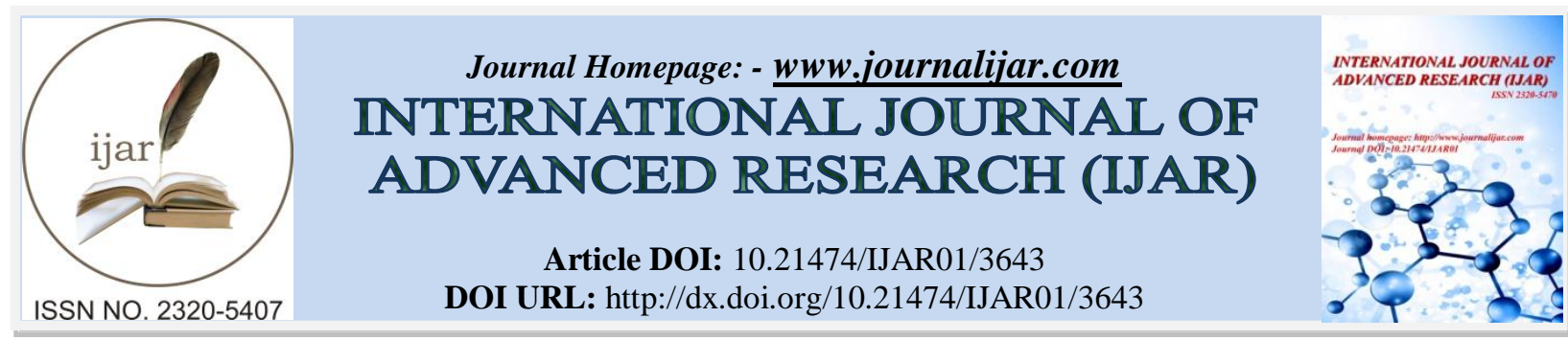

RESEARCH ARTICLE

\title{
KINETICS AND MECHANISM OF THE HYDROLYSIS OF 4-HYDROXYBIPHENYL PHOSPHATE MONOESTER.
}

1. Cadila Pharmaceutical, Ahmedabad.

Ruchi Singh ${ }^{1}$ And *Shweta Chand ${ }^{2}$.

2. Christ Church College, Kanpur.

\section{Manuscript Info}

Manuscript History

Received: 09 January 2017

Final Accepted: 02 February 2017

Published: March 2017

Key words:-

Kinetics, Hydrolysis, Phosphate

Monoester.

\section{Abstract}

Hydrolysis of 4-hydroxybiphenyl phosphate monoester has been carried out in acid $(\mathrm{HCl})$ Solution at $97 \pm 0.5^{\circ} \mathrm{C}$ and the inorganic phosphate obtained during hydrolysis has been estimated coloremetrically. Pseudo first order rate coefficients have been calculated neutral and conjucated acid species have been found to be reactive and contributed to the overall hydrolysis in the acid region. The calculated rate coefficients are in good agreement with the experimentally observed ones. The effect of temperature, solvent and substrate concentration on the rate of hydrolysis have been studied. The results suggest that the hydrolysis of monoester occurs by the cleavage of $\mathrm{P}-\mathrm{O}$ bond fission.

Copy Right, IJAR, 2017,. All rights reserved.

\section{Introduction:-}

The effect of the substituents, the hydrolysis of aryl phosphate esters having C-O- $\mathrm{P}^{1-3}$ linkages have been studied exhaustively by Mhala etal ${ }^{4-6}$ and established that the substituents of graded polarity ${ }^{7-8}$ not only affect the rection rates but also alter the course of the reaction path. Bunton etal ${ }^{9}$ found that acid catalyzed hydrolysis occurs only when an electron attracting substituent is present in the aryl moiety as in nitrophenyl phosphate monoester ${ }^{10}, 4-$ chlorophenyl phosphate monoester ${ }^{11}$ and 2,6-dimethylphenyl phosphate monoester ${ }^{12}$ showed only feeble acid catalysis while 4-bromo-2,6-dimethylphenyl phosphate monoester showed acid catalysis.

\section{Material and Methods:-}

\section{Preparation of mono-4-hydroxybiphenyl phosphate:-}

Mono-4-hydroxybiphenyl phosphate ester have been prepared by general method ${ }^{13}$. Took $17.0 \mathrm{gm}$ of 4hydroxybiphenol in a round bottom flask with $200 \mathrm{ml}$ of dry benzene. $9.0 \mathrm{ml}$ of phosphorus oxytrichloride $\left(\mathrm{POCl}_{3}\right)$ was added drop by drop with constant stirring to the ice-cooled phenol with the help of separating funnel in about hlf an hour after the addition of $\mathrm{POCl}_{3}$. It was refluxed for about 48 hours on the soxhlet heater at constant temperature $85^{\circ} \mathrm{C}$ in order to ensure complete reaction and then distilled at reduce pressure. The first fraction of benzene and unreacted $\mathrm{POCl}_{3}$ was removed by distillion at $\mathrm{b}_{60}, 40-50^{\circ} \mathrm{C}$.

The second fraction of a pungent smelling liquid,which was supposed to be 4-hydroxybiphenyl phosphate dichloride was distilled at $\mathrm{b}_{75}, 90-120^{\circ} \mathrm{C}$.It was dissolved in $100 \mathrm{ml}$ of ice cooled water and kept at low temperature overnight. The 4-hydroxybiphenyldihydrogen phosphate which was extracted with solvent ether.After removing the 
solvent ether a white coloured crystalline solid and it was identified to be mono-4-hydroxybiphenyl phosphate with the following physical characteristics.

1. Melting point (observed) $=180^{\circ} \mathrm{C}$

2. Theoretical percentage of " $\mathrm{P} "=12.40 \%$

3. Observed percentage of "P" $=13.40 \%$

4. The Infrared spectrum of monoesters showed the appearance of absorption bands characteristics of-

OH $=3500-3265 \mathrm{~cm}^{-1}$

CH $=3050-2891 \mathrm{~cm}^{-1}$

C $=\mathrm{C}=1640-1580 \mathrm{~cm}^{-1}$

P-O $=1385-1290 \mathrm{~cm}^{-1}$

C_O_P $=1200-1150 \mathrm{~cm}^{-1}$

$\overline{\mathrm{P}}_{-} \mathrm{OH}=1040-976 \mathrm{~cm}^{-1}$

Substituted aromatic ring $=800-710 \mathrm{~cm}^{-1}$

Above characteristics confirm the structure of mono-4-hydroxybiphenyl phosphate.

\section{Result and Discussion:-}

Hydrolysis of mono-4-hydroxybiphenyl phosphate was kinetically studied in 0.1 to $6.0 \mathrm{~mol} \mathrm{dm}{ }^{-3} \mathrm{HCl}$ at $97 \pm 0.5{ }^{0} \mathrm{C}$ Psuedo first order rate coefficients have been summarized in table-1

$\mathrm{pH}-\log$ rate profile of mono -4-hydroxybiphenyl phosphate at $97 \pm 0.5^{\circ} \mathrm{C}$

\begin{tabular}{|c|c|c|c|}
\hline $\mathrm{HCl}\left(\mathrm{mol}_{\mathrm{dm}}{ }^{-3}\right)$ & $\mathrm{P}^{\mathrm{H}}$ & $10^{5} . \mathrm{Ke}\left(\mathrm{mol} \cdot \mathrm{dm}^{-3} \mathrm{~min}^{-1} \mathrm{Obsd}\right)$ & $5+\log \mathrm{Ke}$ \\
\hline 6.0 & -0.778 & 42.61 & 1.63 \\
\hline 5.0 & -0.669 & 82.18 & 2.91 \\
\hline 4.0 & -0.602 & 154.54 & 2.19 \\
\hline 3.5 & -0.544 & 147.96 & 2.17 \\
\hline 3.0 & -0.544 & 147.96 & 2.14 \\
\hline 3.0 & -0.477 & 138.82 & 2.10 \\
\hline 2.5 & -0.397 & 126.34 & 2.07 \\
\hline 2.0 & -0.300 & 117.55 & 2.02 \\
\hline 1.5 & -0.176 & 104.84 & 1.97 \\
\hline 1.0 & 0.000 & 92.80 & 1.87 \\
\hline 0.5 & 0.301 & 74.36 & 1.86 \\
\hline 0.4 & 0.400 & 72.21 & 1.84 \\
\hline 0.3 & 0.520 & 69.66 & 1.90 \\
\hline 0.2 & 0.700 & 79.02 & 2.01 \\
\hline 0.1 & 1.000 & 93.60 & 2.11 \\
\hline Buffers- & 1.24 & 102.38 & 2.12 \\
\hline Composition of buffers & 2.20 & 127.58 & 2.14 \\
\hline & 3.33 & 132.81 & 2.10 \\
\hline & 4.17 & 138.74 & 2.05 \\
\hline & 5.60 & 126.38 & 2.11 \\
\hline
\end{tabular}




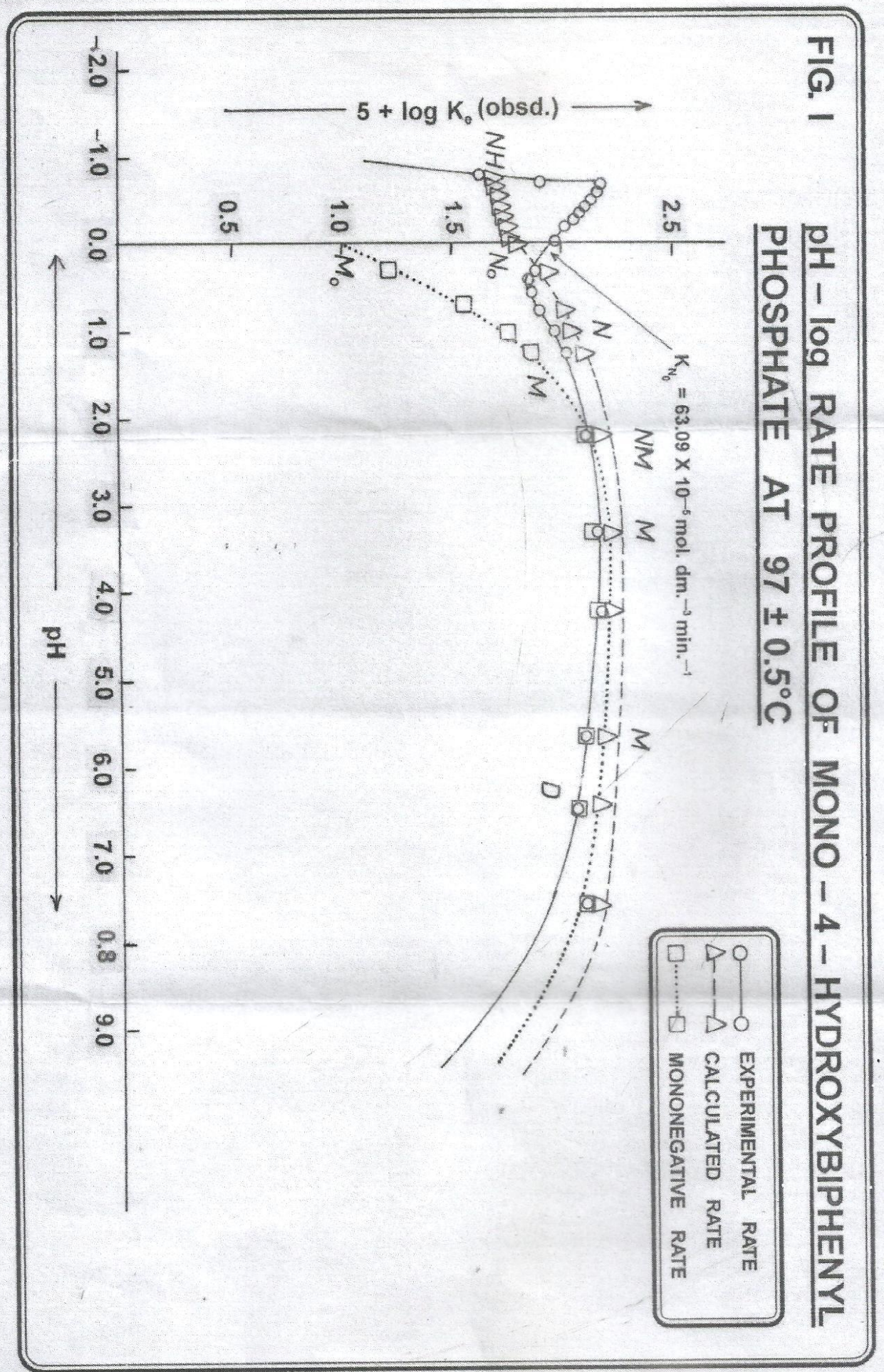


A plot(fig-1) of pH-log rate of hydrolysis increases with increase in acid molarity . The rate maxima is at 4.0 mol $\mathrm{dm}^{-3} \mathrm{HCl}$ and it gradually falls with further increase in acid molarity. The rate maxima or bend of $\mathrm{pH}$ log rate profile in acid region have also been found in some other cases. In organic amide system, similar rate maxima was observed and was supposed due to full conversion into their conjugate acid species the rate decrease is attributed to the lowering of concentration of attacking nucleophile taking part in the reaction, although it appears that there is no similarity in rate maxima with amides as it is not possible due to complete protonation because there is a small variation in temperature coefficient before and after rate maxima and it may be taken as an indication for the absence of maximum protonation. The rate maxima in mono-4-hydroxybiphenyl phosphate may be due to either ionic strength effect or acid catalyzed hydrolysis or due to both.

The initial decrease in rate hydrolysis may be attributed to the decrease in the concentration of more reactive mononegative species. Increase in rate in the region 1.0 to $4.0 \mathrm{~mol} \mathrm{dm}{ }^{-3} \mathrm{HCl}$ may be due to either acid catalyzed hydrolysis or increase in the reactivity of neutral species by ionic strength effect. Therefore effect of ionic strength was studied by carrying out kinetic runs at different ionic strength maintained constant by adding appropriate mixtures of $\mathrm{KCl}$ and $\mathrm{HCl}$. The plots of the rate constant of acid hydrolysis vs acid molarity at different ionic strengths are given in table-2.

Hydrolysis of mono-4-Hydroxybiphenyl phosphate at constant ionic strength at $97 \pm 0.5^{0} \mathrm{C}$

Composition

\begin{tabular}{|c|c|c|c|}
\hline Ionic strength $(\mathrm{u})\left(\mathrm{mol}_{\mathrm{dm}}{ }^{-3}\right)$ & $\mathrm{HCl}\left(\mathrm{mol} . \mathrm{dm}^{-3}\right)$ & $\mathrm{KCl}\left(\mathrm{mol} . \mathrm{dm}^{-3}\right)$ & $10^{-5} \mathrm{Ke}\left(\mathrm{mol} . \mathrm{dm}^{-3} \cdot \mathrm{min}^{-1}\right)(\mathrm{Obsd})$ \\
\hline 1.0 & 0.2 & 0.8 & 61.87 \\
\hline 1.0 & 0.4 & 0.6 & 66.16 \\
\hline 1.0 & 0.6 & 0.4 & 71.66 \\
\hline 1.0 & 0.8 & 0.2 & 97.68 \\
\hline 1.0 & 0.0 & 0.0 & 56.59 \\
\hline 2.0 & 0.2 & 1.8 & 64.91 \\
\hline 2.0 & 0.5 & 1.5 & 76.80 \\
\hline 2.0 & 1.0 & 1.0 & 87.05 \\
\hline 2.0 & 1.5 & 0.5 & 93.84 \\
\hline 2.0 & 1.8 & 0.2 & 117.55 \\
\hline 2.0 & 2.0 & 0.0 & 58.67 \\
\hline 3.0 & 0.5 & 2.5 & 65.20 \\
\hline 3.0 & 1.0 & 2.0 & 73.23 \\
\hline 3.0 & 1.5 & 1.5 & 84.04 \\
\hline 3.0 & 2.0 & 1.0 & 92.18 \\
\hline 3.0 & 2.5 & 0.5 & 138.82 \\
\hline 3.0 & 3.0 & 0.0 & \\
\hline
\end{tabular}

Three linear plots show the acid catalyzed hydrolysis of mono-4-hydroxybiphenyl phosphate at three different ionic strengths $(1.0 \mathrm{u}, 2.0 \mathrm{u}, 3.0 \mathrm{u})$

The intercepts on the rate axis are the neutral rates $\left(\mathrm{K}_{\mathrm{N}}\right)$ which decrease with the increase in ionic strength showing ionic acceleration effect on the hydrolysis of monoester via its neutral species therefore the calculated rates were obtained by equ (1)

$$
\mathrm{Ke}=\mathrm{K}_{\mathrm{H}} \cdot \mathrm{C}_{\mathrm{H}}+\mathrm{K}_{\mathrm{N}}
$$

Where $\mathrm{Ke}, \mathrm{K}_{\mathrm{H}}, \mathrm{C}_{\mathrm{H}}$ and $\mathrm{K}_{\mathrm{N}}$ are experimental rates acid catalyzed rates and neutral rates respectively. The plot of mono 4-hydroxybiphenyl phosphate shows that three plots are intersecting the rate axis at different points (fig.2) hence this indicates in addition to conjugate acid species the presence of some other species.

Since it is established fact that mononegative species cannot be reactive at higher acidities i.e more than $1.0 \mathrm{~mol}^{\mathrm{d}} \mathrm{dm}^{-}$ ${ }^{3} \mathrm{HCl}$, so the neutral species participation may be expected together with conjugate acid species as it is evident that straight lines are intersecting the rate axis at different points which shows the contribution of neutral species at different acid concentration is varying definitely. 
$\mathrm{K}_{\mathrm{H}^{+}}$is a slope of linear curve and its value decrease with the increase in ionic strength. It is an ionic retarding effect which indicates the mono-4-hydroxybiphenyl phosphate undergoes acid catalyzed hydrolysis with negative of ionic strength. The slope of these curves represents the specific acid catalyzed rates at the ionic strength which also decrease with the increase in ionic strength. Thus both specific neutral rates are subjected to negative effect of ionic strength. The neutral rates may be calculated using second empirical term of Debye - Huckel equation ${ }^{14-15}$ and modifying it logarithmically.

$$
\log \mathrm{K}_{\mathrm{N}}=\log \mathrm{K}_{\mathrm{NO}}+\mathrm{b}_{\mathrm{N}} \cdot \mathrm{U}
$$

And its logarithmic form can be represented as

$$
\begin{gathered}
5+\log K_{N}=5+\log K_{N o}+b_{N} \cdot u \\
\text { Where } b_{N}=b_{N} / 2.303
\end{gathered}
$$

In equ ( 2) $\mathrm{K}_{\mathrm{N}}, \mathrm{K}_{\mathrm{NO}}, \mathrm{b}_{\mathrm{N}}$ and u respectively are specific neutral rates at zero ionic strength and the slope of the linear curve and ionic strength ( fig. not shown)

The intercept on the rate axis of such a plot i.e $\log \mathrm{K}_{\mathrm{N}}$ is found to be different thus the increase in specific neutral rate is due to $\left(b_{N} \cdot u\right)$ factor supporting ionic acceleration effect specific neutral rates calculated by equcation 2 are almost different from the experimental rate upto 4.0 mol. $\mathrm{dm}^{-3} \mathrm{HCl}$ and shown in Table-1. The rates above $4.0 \mathrm{~mol}^{-\mathrm{dm}^{-3} \mathrm{HCl}}$ however deviate probably due to decrease in the reactivity of the neutral form as a result of decrease in water acidity therefore the rates beyond 4.0 mol. $\mathrm{dm}^{-3} \mathrm{HCl}$ were calculated employing the Bronsted-Bjerrum equcation ${ }^{16-17}$

$$
\mathrm{Ke}=\mathrm{K}_{\mathrm{H}}{ }^{+} \mathrm{C}_{\mathrm{H}}{ }^{+} \operatorname{expb}_{\mathrm{H}+} \cdot \mathrm{u}\left(\mathrm{a}_{\mathrm{H} 20}\right)^{\mathrm{n}}+\mathrm{K}_{\mathrm{NO}} \cdot \operatorname{expb}_{\mathrm{N}} \cdot \mathrm{u}\left(\mathrm{a}_{\mathrm{H} 2 \mathrm{O}}\right)^{\mathrm{n}}
$$

And its logarithmic form can be represented as

$5+\log \mathrm{Ke}+5+\log \mathrm{K}_{\mathrm{H}}{ }^{+}+\log \mathrm{C}_{\mathrm{H}}{ }^{+}+\mathrm{b}_{\mathrm{H}}{ }^{+} \mathrm{u}+\mathrm{nlog}\left(\mathrm{a}_{\mathrm{H} 20}\right)+5+\log \mathrm{K}_{\mathrm{NO}}+\mathrm{b}_{\mathrm{N}} \cdot \mathrm{u}+n \log \mathrm{a}_{\mathrm{H} 2 \mathrm{O}}$

Where $\left(\mathrm{a}_{\mathrm{H} 2 \mathrm{O}}\right)^{\mathrm{n}}$ represents the water acidity parameter.

The values of $\mathrm{n}=2,3$ were calculated for 5.0 and $6.0 \mathrm{~mol} \mathrm{dm}^{-3} \mathrm{HCl}$ respectively. The experiemental rates thus calculated are in good agreement with the theoretical rates. The thermodynamic parameter for the reaction at 3.0 and $5.0 \mathrm{~mol} . \mathrm{dm}^{-3} \mathrm{HCl}$ were found to be $\mathrm{E}=22.70$ and $22.06 \mathrm{~K}^{-c a l . \mathrm{mol}^{-1}}$ frequency factor $(\mathrm{A})=5.89 \mathrm{X} 10^{8}$, $1.46 \times 10^{8} \mathrm{Sec}^{-1}$ and $\mathrm{S}=-20.83,-23.60$ e.u.These values indicate the biomolecular nature of hydrolytic reaction.

The acid hydrolysis of monoester, therefore,involves bimolecular attack of water on phosphorus of the neutral species as showen in schemes I and II.

Scheme- I

\section{(a) FORMATION OF CONJUGATE ACID SPECIES BY \\ FAST PRE-EQUILIBRIUM PROTON TRANSFER:}

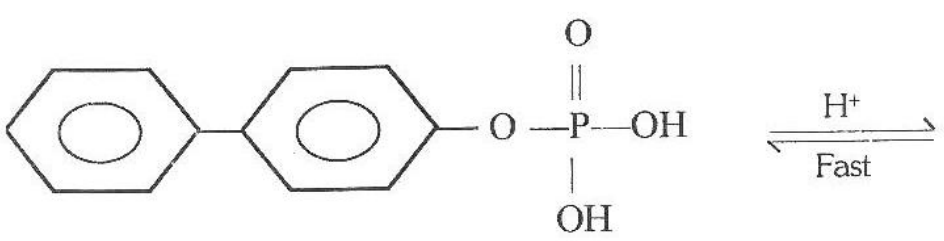

(Neutral species) 
(a) FORMATION OF CONJUGATE ACID SPECIES BY

\section{FAST PRE-EQUILIBRIUM PROTON TRANSFER:}

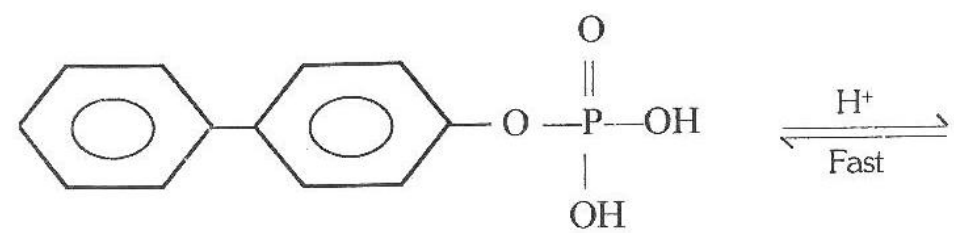

(Neutral species)

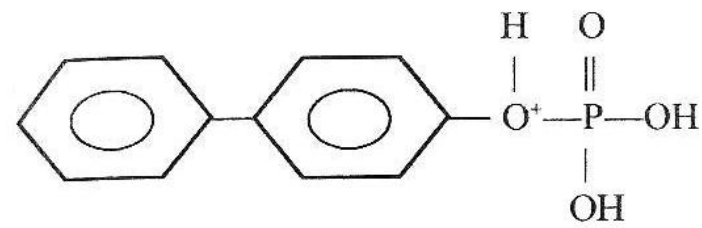

(Conjugate acid species)

b) BIMOLECULAR NUCLEOPHILIC ATTACK OF WATER ON PHOSPHORUS OF CONJUGATE ACID SPECIES INVOLVING P-O BOND FISSION $\mathrm{S}_{\mathrm{N}^{2}}(\mathrm{P})$ :
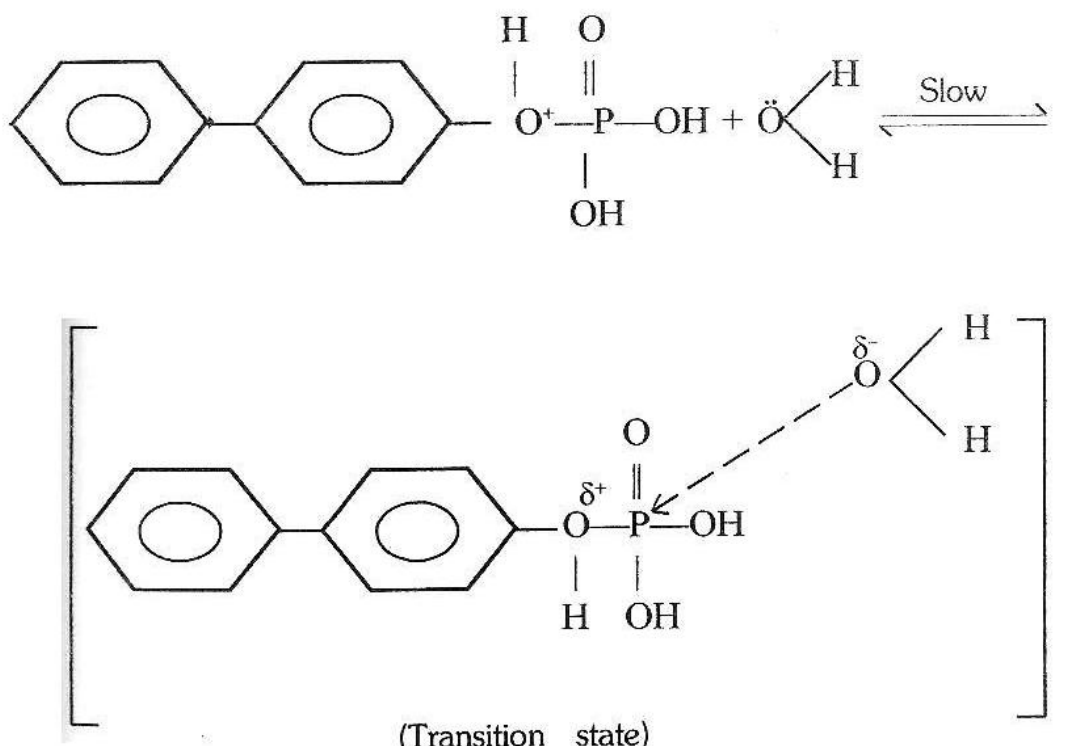

(Transition state) Fast 
BIMOLECULAR NUCLEOPHILIC ATTACK OF WATER

\section{ON PHOSPHORUS ATOM WITH $\mathrm{P}-\mathrm{O}$ BOND}

FISSION:

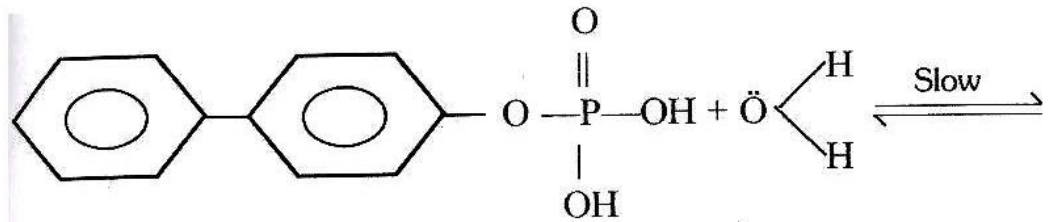

(Neutral species)

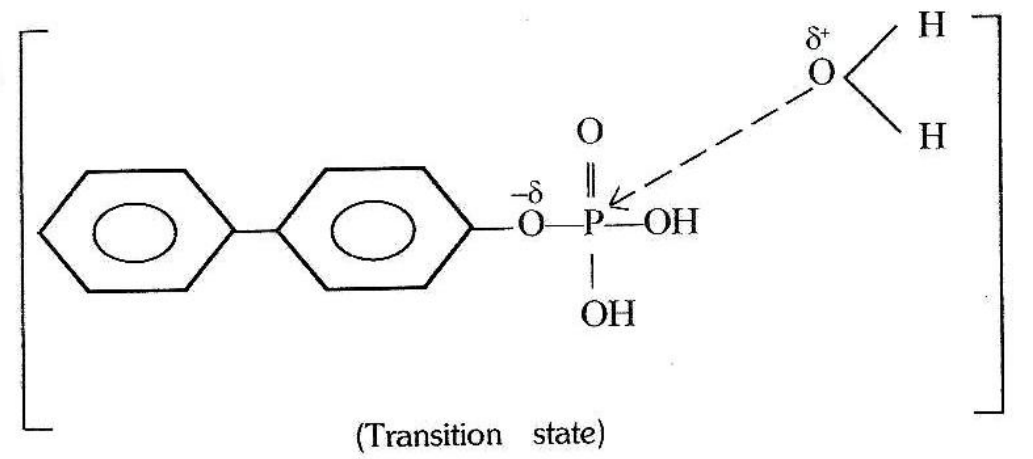

Fast
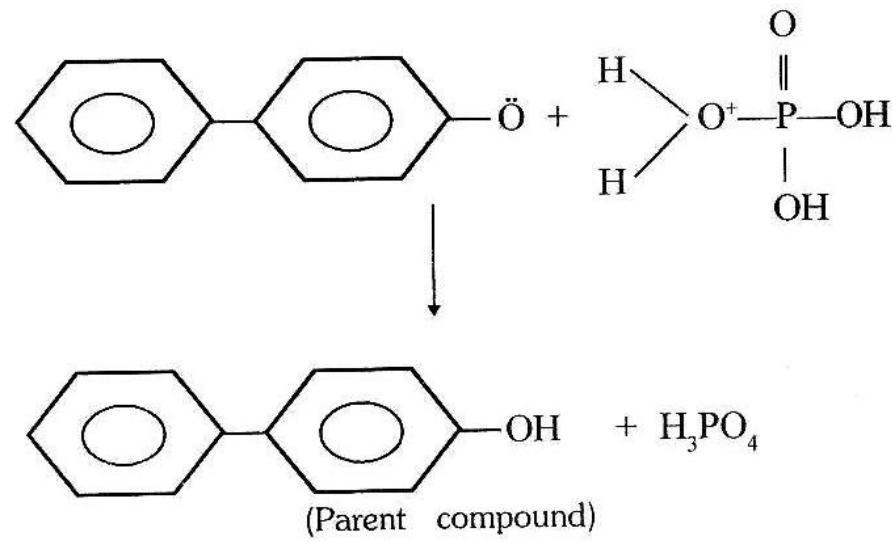


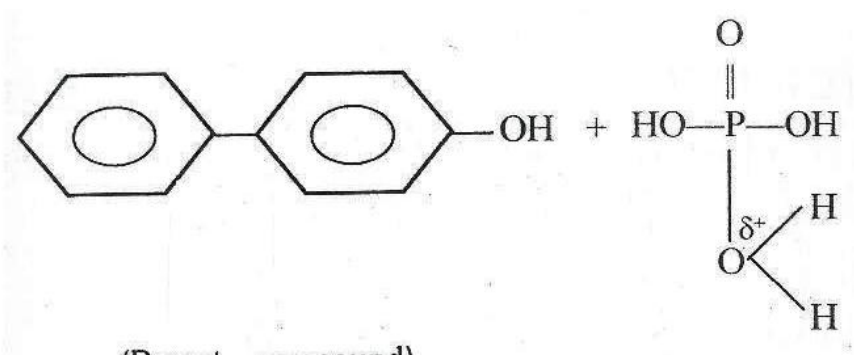

(Parent compound)

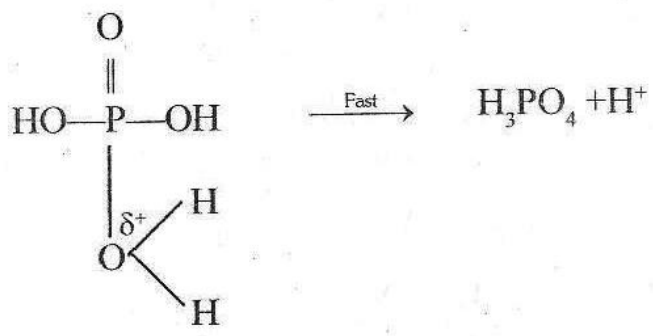

\section{Refrences:-}

1. Humphy ,T.M; Forconi Marcello, Willam Nicholos; Hengge, H.C; J of American Chemical Soc. 124(50) 14860-14861 (2002).

2. Kadam.R; Dixit,V.K; Agarwal,A;Parihar,P.S; Asian J of Chemistry Vol (XVI)3758 (2008).

3. Singh.R; Chand,S; Global J for Research analysis Vol.4(8) pg 13-16(2015).

4. Mhala.M.M; Patwardhan,M.D; \& Kasturi,G; Indian J of Chem;7:149(1969)

5. Mhala,M.M; Jagdale,M.H; Indian J of Chem.8,147(1970)

6. Mhala,M.M;Kushwaha,R.S;. Indian J of Chem Pub.No.3/4 Sec.A 4263A-H(1989).

7. Jacklak,C.K; Ph.D. Thesis Jiwaji University, Gwalior(1972).

8. Tiwari,B.K; Kushwaha,R.S; J of Science Shivaji University Kolhapur Vol.23(1986).

9. Banard,P.W.C;Bunton,C.A;Killerman,D;Mhala,M.M;Silver,C.A;Vermon;\& Welch,V.A;J.Chem.Soc.B227(1966).

10. Chaudhary,S;Ph.D;Thesis Jiwaji university, Gwalior(1994).

11. Mhala,M.M;Ph.D.Thesis London(1958).

12. Tiwari,B.K;David,S;Solonki,A;Kanta;Asian J of Chemistry.Vol.14(1)39-52(2002).

13. Rudert,P;J.Chem.Soc.a.1:323-324(1993).

14. Debey \& Huckel,Physic,Z;24,185-305(1923).

15. Barnard,P.W.C;Bunton,C.A;Killerman.D;Mhala,M.M;Silver,B;J.Chem.Soc;Sec-B,227-235(1996).

16. Bronsted,J.N.Z;Physik,Chem 102,169(1992),115,237(1925).

17. Bjerrum,N;Z.Physik.Chem;108,82(1924),118,251(1925). 